\title{
Corpos enxutos, corpos desnudos: a moda na imprensa ilustrada carioca e a disseminação de uma nova estética corporal (1920-1940)
}

Slim bodies, naked bodies: fashion in Rio de Janeiro's illustrated press and the dissemination of a new aesthetic body (1920-1940)

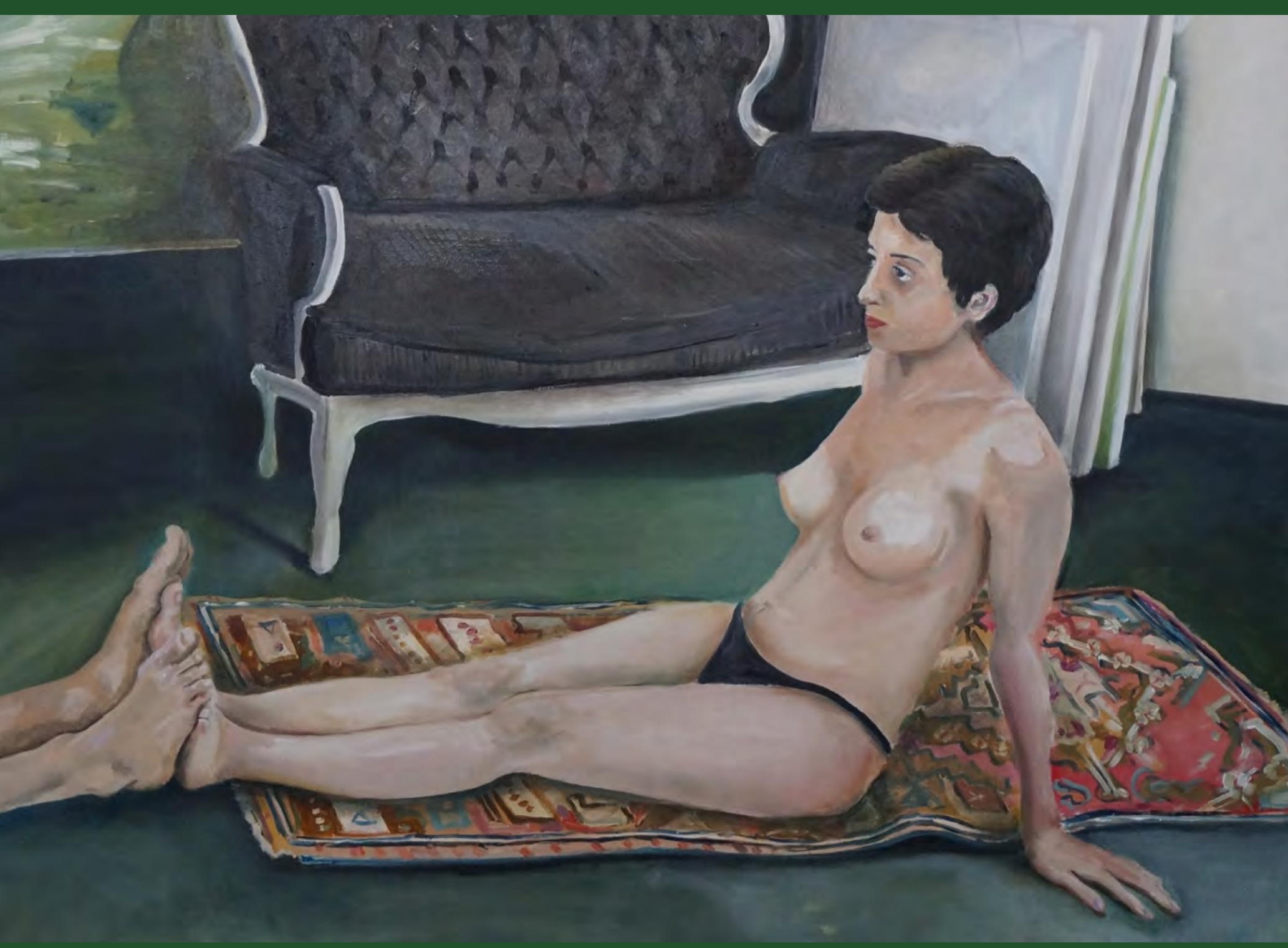




\section{Júlia Mello ${ }^{1}$}

ORCID: https://orcid.org/0000-0001-8454-2453

[resumo] Este artigo tem por objetivo apresentar a construção de diálogos em torno das novas exigências do corpo da brasileira visíveis a partir da década de 1920, considerando a análise da moda disseminada nas revistas ilustradas cariocas Para todos, Careta e $O$ Malho. 0 período escolhido - de 1920 a 1940 - é de significativas mudanças sociais, culturais e econômicas no Brasil e também do desenvolvimento dos discursos sobre as práticas corporais e esportivas que contribuíram para a ideia de cuidado corporal como algo atrelado à saúde, à beleza e à força produtiva. A análise dos periódicos é realizada a partir de uma discussão teórica que entrelaça história do corpo, questões de gênero, moda, discursos médicos e normativos. Dessa forma, considera autores como Georges Vigarello (2011), Denise Sant'anna (2016), Carmen Lúcia Soares (2011) e Michel Foucault (1999). Os resultados revelam a construção de olhares pautados em convenções e estereótipos, limitadores de possibilidades individuais e sociais, a partir da imagem da mulher na fotografia, no texto ou na ilustração. Imagens que reafirmam os valores dominantes, a hierarquia entre os sexos.

\section{[palavras-chave] Corpo. Gênero. Imprensa. Moda.}

[abstract] This article aims to present dialogues about the new standards of Brazilian women's bodies visible in the 1920's by considering an analysis in the fashion displayed in Rio de Janeiro's magazines Para todos, Careta and O Malho. The 1920's/1940's is a period of significant social, cultural and economic changes in Brazil and it is also the context where the development of the discourses around corporal and sports practices contributed to the idea of corporal care as something related to health, beauty and productivity. The analysis of the magazines is based on a theoretical discussion that intertwines body history, gender issues, fashion, medical and normative discourses. Thus, authors such as Georges Vigarello (2011), Denise Sant'anna (2016), Carmen Lúcia Soares (2011) and Michel Foucault (1999) are considered. The results reveal the construction of gazes based on conventions and stereotypes, limiting individual and social possibilities, for the image of women, whether in photography, text or illustration. The images included in the magazines reaffirm the dominant cultural values, including the hierarchy between the sexes.

[keywords] Body. Gender. Press. Fashion.

Recebido em: 13-01-2019

Aprovado em: 22-07-2019

\footnotetext{
${ }^{1}$ Doutoranda no Programa de Pós-Graduação em Artes da Universidade Federal do Rio de Janeiro com período sanduíche na Kendall College of Art and Design - Ferris State University (2020). Bolsista CNPq. E-mail: juliaalmeidademello@gmail.com. Lattes: http://lattes.cnpq.br/2648924540669238.
} 


\section{Introdução}

A moda disseminada nas revistas ilustradas cariocas Para todos, Careta e $O$ Malho permite uma análise da construção de diálogos em torno das novas exigências do corpo da brasileira visíveis a partir da segunda década do século XX. De 1920 a 1940, o Brasil passava por significativas mudanças sociais, culturais e econômicas e esse também foi o período de desenvolvimento dos discursos sobre as práticas corporais e esportivas que contribuíram para a ideia de cuidado corporal como algo atrelado à saúde, à beleza e à força produtiva. Nesse contexto, havia o fortalecimento da veiculação de produtos da moda que valorizavam silhuetas enxutas e que revelavam partes antes não vistas. Atrizes hollywoodianas passavam a ser frequentemente utilizadas como referência em diferentes looks para o dia e para a noite, bem como se popularizavam suas dietas, seus exercícios e seus "segredos de beleza". A atenção com o volume corporal aumentava e o glamour tornava-se o representante da silhueta longilínea e magra. Um corpo esbelto e atlético era visto como sinônimo de elegância e requinte, sobretudo durante o verão nas areias.

0 estilo esportivo constituía-se como uma nova possibilidade de performance, sendo vendido sob o slogan de conforto e liberdade. Com ele, o corpo ganhava destaque com peças do vestuário que conferiam maior maleabilidade e influenciavam a moda de lazer com transparência, sendo comum o uso de tecidos como gaze, tule e musseline. Para as mulheres, o estilo era ainda mais enfático e provocava as corpulentas já que a cada temporada de verão uma nova tendência surgia com camadas a menos de tecidos e corpos cada vez mais desnudos.

Baseando-nos nas premissas acima, buscamos, a seguir, respostas para as seguintes questões: que corpos apareciam vestindo as peças da moda? Quais comportamentos eram sugeridos às mulheres nas páginas das revistas? Como as mais gordas eram vistas e representadas? Esses pontos permitem entrelaçamentos e alinhavos para o entendimento da potência da cultura da moda (combinada com outros importantes canais, como a medicina e a imprensa) para a construção da obsessão pelo contorno magro e escultural.

Lançamos uma análise dos periódicos selecionados tendo como base um debate teórico que entrelaça história do corpo, questões de gênero, moda e discursos médicos e normativos. Nesse ponto, autores como Georges Vigarello (2011), Anne-Marie Sohn (2011), Denise Sant'anna (2016), Carmen Lúcia Soares (2011) e Michel Foucault (1999) são de grande relevância. Vigarello (2011), por exemplo, traz um recorte da história do corpo no Ocidente direcionado à evolução dos treinos esportivos, mostrando como eles foram sendo incorporados no dia a dia das pessoas, configurando-se como forma de lazer. Lazer este que estava cada vez mais associado às performances do corpo, mostradas pelo desnudamento, pela redução de camadas de tecido para a revelação da pele e dos contornos (SOHN, 2011). Ao mesmo tempo, Denise Sant'anna (2016) indica as mutações do olhar sobre as dimensões corpóreas no contexto brasileiro e o aumento da discriminação da corpulência na mulher com o passar dos anos. 0 estudo de Carmen Lúcia Soares (2011) permite-nos dirigir essas questões para o campo da moda, reconhecendo que as normatizações do corpo exploradas por Michel Foucault (1999) foram sendo absorvidas por meio da ideia de conforto, elegância e eficiência, como veremos a seguir. 


\section{Corpos atléticos adornados com a moda}

Conforme indica Soares (2011), os anos de 1920 a 1940 constituem um período de grandes transformações na cultura da vestimenta brasileira que carrega uma nova sensibilidade graças ao estilo esportivo. Devemos lembrar que o recuo do pudor corporal passa a ser esboçado a partir da belle époque e, de acordo com Sohn (2011), vai se acelerando no intervalo entre guerras a partir da superação progressiva das barreiras de tradições seculares.

Com a influência esportiva do início do século XX, as roupas ficaram mais curtas, ainda em tecidos escuros, até que, depois da Primeira Guerra, passaram a ser produzidas em cores claras. Os homens usavam calções de cintura alta e as mulheres maiôs com decotes mais acentuados. 0 corpo se despia em busca de um bronzeado perfeito. Bronzeado que, segundo Vigarello (2011), se glorificava e se tornava canônico, trazendo a ideia de beleza ao "ar livre". Com esse desnudamento, os cânones de beleza mostravam-se mais exigentes, "o modelo do homem e da mulher magros e longilíneos predomina. Com a nudez do verão, é necessário ainda por cima exibir músculos firmes" (VIGARELLO, 2011, p. 111). A partir de então, como destaca o historiador, "natureza e nudez têm uma outra presença; força e musculatura, um outro valor" (VIGARELLO, 2011, p. 215).

Nesse contexto, as roupas aludem à educação do corpo (SOARES, 2011), contribuindo ao mesmo tempo para o sentido de pertencimento e de individuação. Com o desenvolvimento da medicina e das práticas esportivas com o apoio da educação física, as opiniões com justificativas morais, estéticas e higiênicas tornavam-se cada vez mais presentes na imprensa. Esses discursos, descritos por Foucault (1999) como disciplinares, manifestavam-se com uma peculiaridade de formas modernas que contribuíam para o aumento da utilização do corpo em diversas esferas. Como sugere Sandra Bartky, "agora exige-se mais do corpo que mera lealdade política ou que a apropriação dos produtos de seu trabalho: a nova disciplina invade o corpo e busca regular suas forças e operações, a economia e eficiência do seu movimento" ( BARTKY, 1997, p. 93)².

Na edição de janeiro de 1931 da revista Para todos, a seção "L de Elegância", que apresentava as últimas tendências da moda feminina, confirmava a busca pelos "modernos hábitos" que incluíam usar tecidos leves e realizar atividades ao ar livre, como jogar peteca ou bola na areia ou praticar natação. Os croquis, como mostra a figura 1, carregam os traços longilíneos, mas atléticos, com leves torneados que podem sugerir uma referência à Gibson girl, de Charles Gibson (1867-1944), baseada em modelos profissionais, amigas e mulheres da família do ilustrador e que correspondia a um padrão de "feminilidade" pautado na norte-americana branca e de classe média. Diversas cenas promoviam atividades físicas como andar de bicicleta, jogar tênis e golfe, cavalgar, nadar, indicando que a "nova mulher" atlética estava na moda e era socialmente aceita.

\footnotetext{
${ }^{2}$ Tradução nossa para "more is required of the body now than mere political allegiance or the appropriation of the products of its labor: the new discipline invades the body and seeks to regulate its very forces and operations, the economy and efficiency of its movements" (BARTKY, 1997, p. 93).
} 
Silvana Goellner (2003) destaca que, no contexto brasileiro, a prática de atividades corporais e esportivas era fortemente incentivada por meio do divertimento e, simultaneamente, da disciplina e que

uma vez divulgada a ideia da necessidade de um cuidado corporal para a aquisição e preservação da saúde, da beleza e da força produtiva, necessárias se fazem atitudes e situações voltadas para a consolidação dessa afirmação. (GOELLNER, 2003, p. 17)

FIGURA 1 - CROQUIS DE MODA CARREGANDO OS TRAÇOS LONGILÍNEOS

E ATLÉTICOS DAS PRIMEIRAS DÉCADAS DO SÉCULO XX
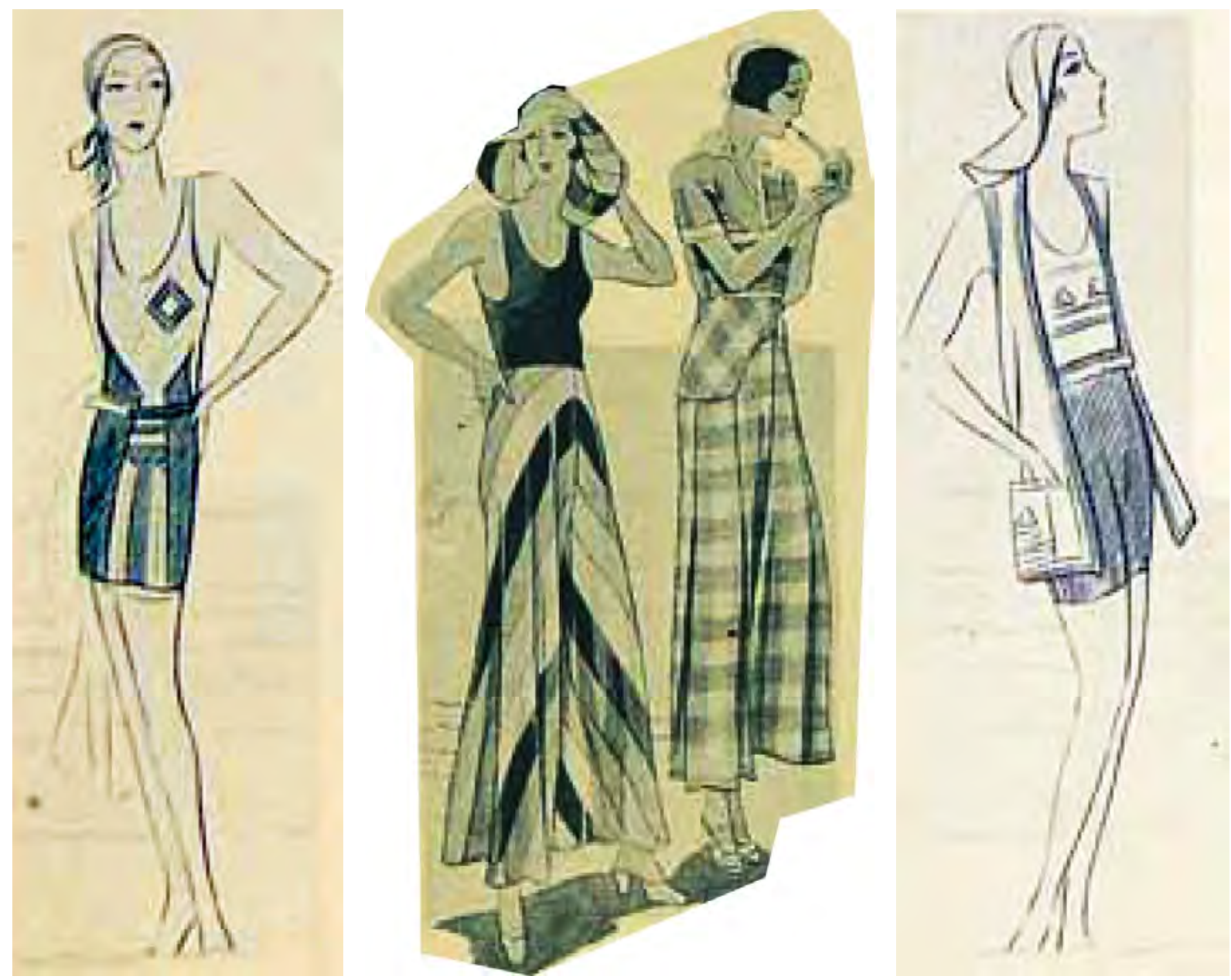

FONTE: L de Elegância. Para todos, Rio de Janeiro, n. 629, 3 jan. 1931, p. 34.

Disponível em: http://objdigital.bn.br/acervo_digital/div_periodicos/para_todos/ para_todos_1931/para_todos_629.pdf. Acesso em: 9 jan. 2018.

Nesse aspecto, há que se destacar a predominância das imagens que reforçam o caráter enfático da moda nos momentos de lazer e na prática de atividades físicas vinculados aos conhecimentos técnicos, científicos, ideológicos, pedagógicos e estéticos do período. 
Das três revistas analisadas, a Para todos é a que mais se direcionava à divulgação da moda e de notícias do mundo do entretenimento. Da mesma editora de O Malho e Careta, com forte participação do designer e cartunista J. Carlos (1884-1950), exibia fotografias e ilustrações que dialogavam com as seções temáticas e os textos, atualizando o universo feminino com looks das estrelas do cinema e os recomendados para as praias no verão.

Os corpos que surgem nas revistas ilustradas remetem a características como juventude, esbelteza, bronzeado, dinamismo, heterossexualidade, riqueza e sofisticação. É importante ressaltar que muitas referências na produção dos desenhos de moda e na construção da estrutura editorial da imprensa brasileira advinham da França e dos Estados Unidos, de revistas como Vogue, Votre Beauté e Life. Sobre esse ponto, Gilles Lipovetsky (2016) destaca que, a partir dos anos 1920, em países europeus e nos Estados Unidos, celebrava-se um modelo de estética feminina que valorizava pernas longas, silhueta esbelta e reta no lugar do corpo frágil e delicado maternal, como símbolo de dinamismo e autocontrole, que traduzia os tempos modernos, da velocidade, das máquinas, da aerodinâmica. Corpo que havia se libertado do espartilho com criações como as de Paul Poiret (1979-1944), mas que se aprisionaria em seu próprio envoltório material. Soares (2011) sugere que até o fim da década de 1920 a presença europeia nos modos, no comportamento e na estética era maior do que a norte-americana, que só ganhou atenção nos anos seguintes graças à forte propaganda do American way of life carregado por uma beleza homogênea que desconsiderava a diversidade étnica.

A Careta dedicava uma seção especial ao padrão cinematográfico. Fundada por Jorge Schmidt (1893-1935), circulou na primeira metade do século passado e é tida como registro de grande relevância para a compreensão da cultura da época, divulgando aspectos da modernidade, da belle époque carioca, do Rio de Janeiro civilizado e cosmopolita. De acordo com Clara Nogueira (2010), a Careta se classifica como revista de variedades, de caráter multiforme e de conteúdo amplamente diversificado, concorrente direta da $O$ Malho na irreverência como suporte editorial. Nomes como Lima Barreto, Emílio de Menezes, Martins Fontes, Olegário Marianno, Luiz Edmundo, os redatores Bastos Tigre e Leal de Souza e Olavo Bilac figuravam na lista de colaboradores que contribuíam com textos de tom jocoso, hilariante e provocador, muitas vezes com assuntos que destacavam a beleza da nova mulher, cosmopolita e elegante. Na seção "Galeria dos artistas da tela”, da edição de janeiro de 1938, temos um exemplo do padrão hollywoodiano ilustrado pela atriz Carole Lombard (19081942), acompanhado do seguinte texto:

Vênus aerodinâmica, é a belesa mais sensacional do momento em Hollywood. Eduardo Kent dedicou-lhe um poema: "Miss Carole Lombard é uma dessas loiras bonecas de cêra que sorriem comercialmente nas vitrines das casas de modas [...]". E ela, segundo o poeta da Broadway, possue um corpo tão formoso que todos os espelhos, enamorados, lhe aprisionam a loira imagem durante dez minutos em suas luzes de cristal, que são grandes pupials rutilantes de desejo [...] “Corpo 
maravilhoso para ilustrar tudo o que é belo, elegante e frívolo: a capa de uma revista de modas, o anuncio de um dentifricio caro, o vidro de um perfume de luxo [...]". [...] padrão cinematográfico de it e sex appeal. (GALERIA dos artistas da tela, 1938, p. 31)

O novo ideal de beleza disseminado por Hollywood era então traduzido pela atriz que, comparada a uma boneca ou um manequim de corpo formoso, loira, representava a frivolidade do consumo. Ela aparece na fotografia com maquiagem destacada, sobrancelhas delineadas, cílios e unhas longos transmitindo os padrões e comportamentos que se disseminavam de Hollywood para o Brasil. Dentro do discurso hegemônico, as mulheres deviam ser ao mesmo tempo ágeis, aerodinâmicas, belas e elegantes para que pudessem representar a pureza da trivialidade. Os indicadores de transformação da "verdadeira" mulher traziam como ponto máximo a beleza como "obrigação" e, ainda que se exigisse corpos ativos, não se descartava a maternidade como destino e a feminilidade como consequência (GOELLNER, 2003).

0 uso de roupas leves como as que a "encantadora lourinha" (figura 2), a atriz Mary Carlisle (1914-2018), vestia era incentivado para passeios, idas a cafés, teatros, cinemas ou caminhadas e práticas de esportes como andar de bicicleta e jogar tênis. Com forte influência do ciclismo, os shorts se popularizavam, variando no comprimento: longos para caminhadas e curtos para as "sedutoras" (SOHN, 2011). Carlisle representa a dominação das mulheres magras, brancas, ativas, jovens nos periódicos da época que anulavam negras, gordas e velhas como modelos de comportamento e estilo a serem seguidos ${ }^{3}$. Essa homogeneização das identidades visuais e comportamentais, além de se relacionar com a construção de um estado satisfatório de saúde, representava exercícios de sociabilidade que afirmavam a mulher em espaços considerados "masculinos", como a rua, o clube, a piscina e os ginásios. Dessa forma, organizava-se um contexto de impulsos da modernização da mulher e da sua autoafirmação na sociedade em meio a discursos progressistas e moralistas, nos quais as "conquistas" se ajustavam aos deveres (GOELLNER, 2003).

Com maior frequência substituía-se o salto alto por sapatos baixos e confortáveis com o apoio dos discursos médicos higienistas que os consideravam nocivos à saúde (SALVETTI, 2014). As roupas destinadas à prática de exercícios e esportes contribuíam para a formação de um estilo que remetesse ao jovial e as peças antes comumente escondidas por baixo de outras, a exemplo das camisetas, passavam a ser utilizadas sem sobreposições. Malhas de jérsei, tricôs leves, lãs e sedas compunham a cartela de tecidos moderna.

\footnotetext{
3 Considerando a questão racial no Brasil, observa-se que, entre as décadas de 1920 e 1930, embora cada vez mais ideologicamente "assimilacionistas" no discurso público, as elites, detentoras do papel central na imprensa, ainda se mostravam social e racionalmente discriminadoras na esfera privada. Foi nesse contexto que a tese do branqueamento começou a adquirir significados, levando à ideia de que os "cruzamentos entre mulatos e brancos favoreceriam o branqueamento não só pela superioridade biológica dos brancos como também pelo fato de que os mulatos preferiam parceiros mais brancos que eles próprios" (STEPAN, 2004, p. 358).
} 


\section{FIGURA 2 - MARY CARLISLE POSA COMO A "ENCANTADORA LOURINHA"}

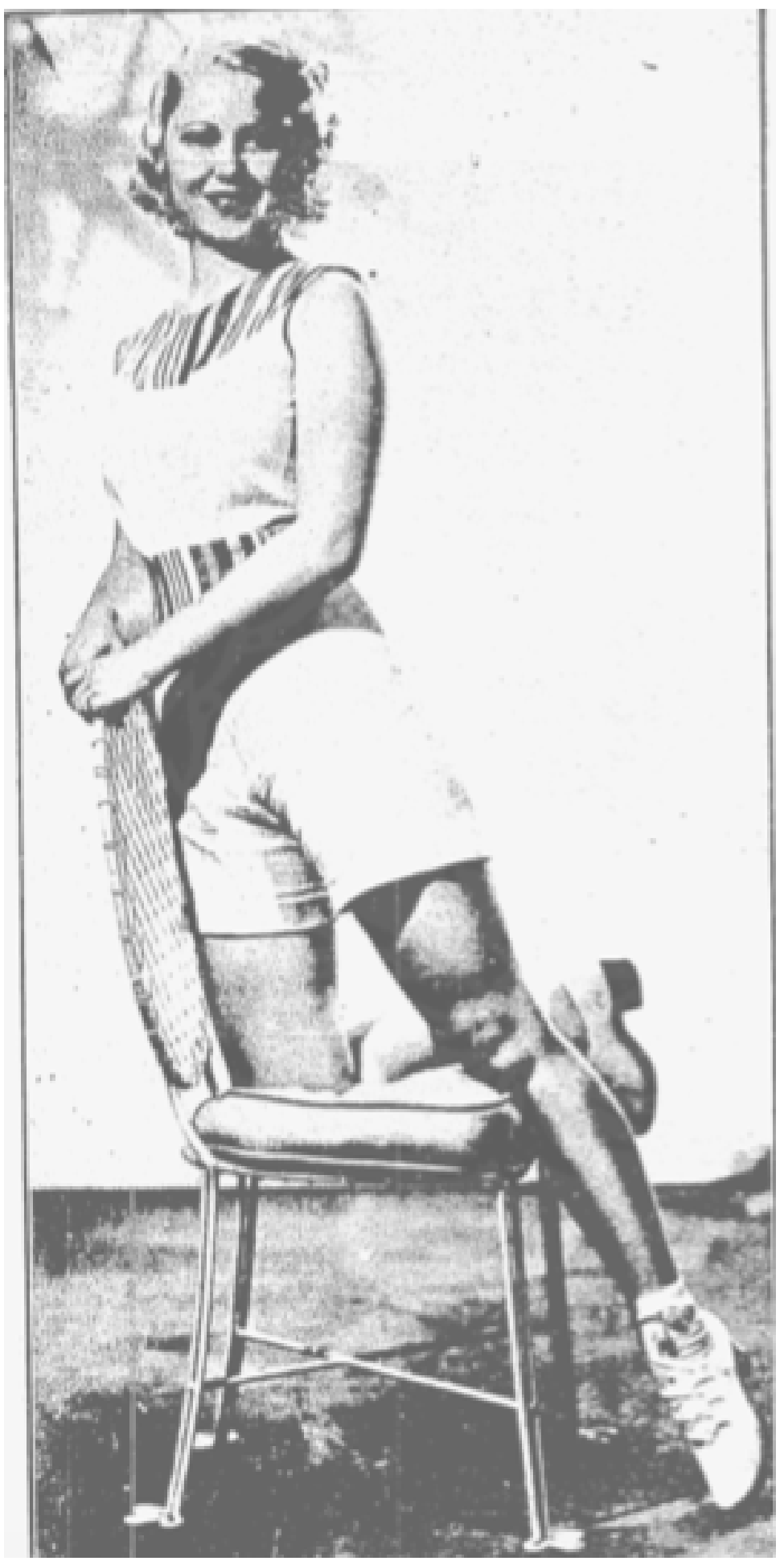

FONTE: Galeria dos artistas da tela. Careta, Rio de Janeiro, n. 1385, 5 jan. 1935, p. 36. Disponível em: http://objdigital.bn.br/acervo_digital/div_periodicos/ careta/careta_1935/careta_1935_1385.pdf. Acesso em: 9 jan. 2019. 
Lipovetsky (2016) reforça que a nova estética corporal se impôs em razão da moda, do cinema, dos esportes e do lazer. "De forma mais geral, os pesos e as medidas que invadem as revistas assinalam a nova obsessão pelas medidas calculadas, por uma beleza medida, por um ideal corporal cada vez mais difícil de alcançar e que exige ações corretivas" (LIPOVETSKY, 2016, p. 91). Os textos e ilustrações contidos nesses materiais eram geralmente produzidos por homens que atribuíam mais ou menos voz às falas das mulheres por meio de temas sobre padrões estéticos, vestuário e conselhos morais, que, por sua vez, selecionavam quais ângulos do corpo seriam destacados ou ocultados (GOELLNER, 2003). Um dos inúmeros exemplos de discursos masculinos diante das silhuetas vibrantes e bronzeadas que "enfeitavam" as praias no verão carioca pode ser visto na Careta, número 15, volume 1, ano 1938, no texto de Nelio Reis, intitulado "A festa das praias":

[...] a belesa da carne, dos corpos buliçosos adivinhados entre as malhas abelhudas dos maillots. E os olhos da gente passeiam deslumbrados ante aquela belesa toda que é bem, como quiz o poeta uma deliciosa promessa de felicidade. (REIS, 1938, p. 28)

Sustentado pela poesia masculina, o discurso direcionado ao corpo feminino faz deste um aperitivo para o olhar do homem. Na mesma revista, no ano de 1922, número 741, a montagem da ilustração com a fotografia (figura 3) parece antecipar a tal "festa das praias" anunciada por Reis, do olhar masculino sobre o corpo feminino. No lado direito da página, isto fica ainda mais evidente com a mulher que caminha no primeiro plano com pernas, braços e colo à mostra, portando peças da moda harmonizadas pela combinação de padrões, tirando a atenção de todos os homens da cena. No lado esquerdo, a mulher com a criança também revela partes do corpo curvilíneo.

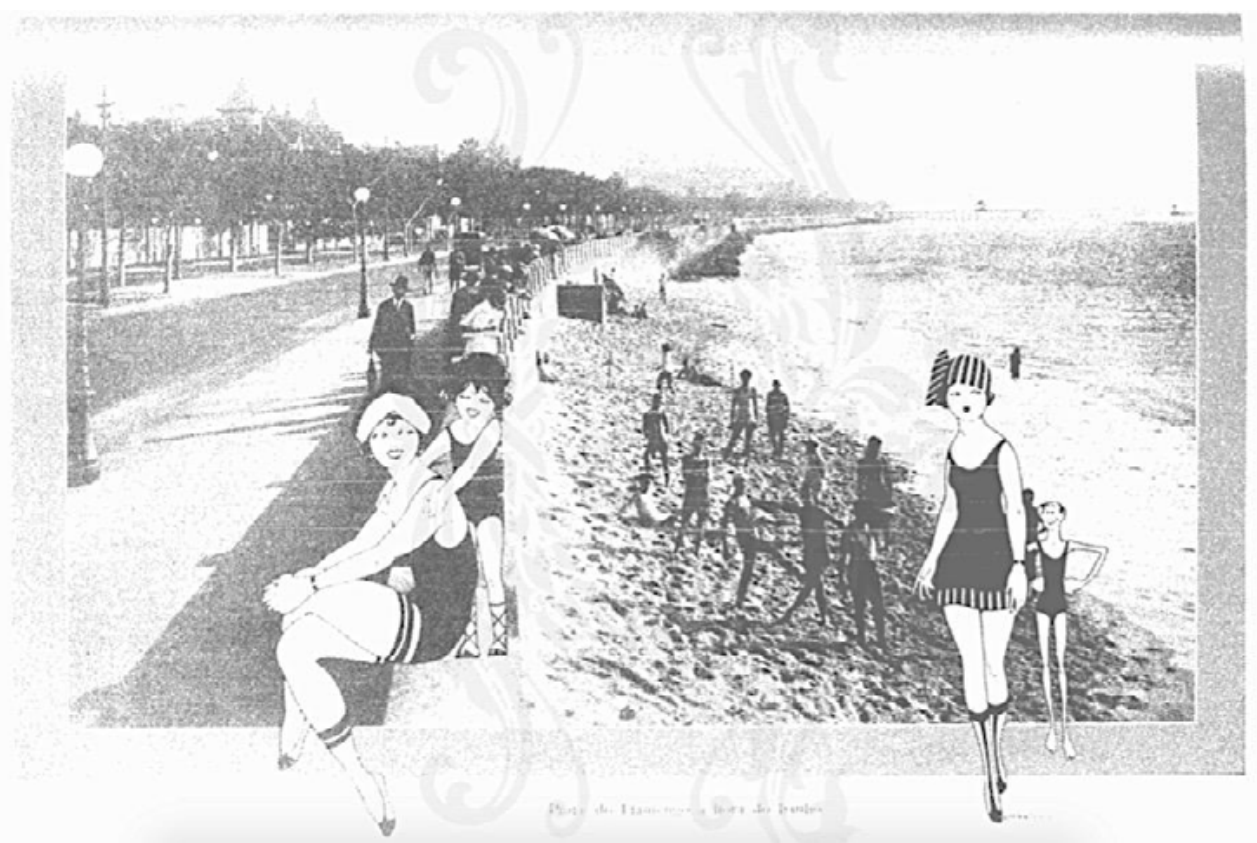

FONTE: Careta. Rio de Janeiro, 2 set. 1922, p. 32-33. Ilustração: J. Carlos. Disponível em: http://objdigital. bn.br/acervo_digital/div_periodicos/careta/careta_1922/careta_1922_741.pdf. Acesso em: 11 jan. 2018. 
Esse ponto merece destaque para a seguinte questão: os corpos das mulheres não são traçados na mesma espessura que o do homem que também é ilustrado. Diferentemente dele, que é retratado como "franzino" ou "magricela"4, elas carregam a "formosura das curvas", para usar um termo bastante recorrente nos textos dos poetas e editores. Mas, cabe lembrar, são esbeltas, não corpulentas, configurando o corpo escultural, atlético e equilibrado que aos poucos fundamentava as novas propostas da medicina e dos cuidados com a higiene no país, atrelado a uma ênfase na educação física.

No Brasil é a partir dos anos 30, por exemplo, que o Estado instituído se empenha em concretizar várias ações no campo específico das práticas corporais e esportivas, identificando a Educação Física e o esporte como espaços de intervenção na educação dos cidadãos, no sentido da valorização do corpo esteticamente belo e do aperfeiçoamento físico de corpos saudáveis e aptos, capazes de enfrentar os desafios da vida modernizada. (GOELLNER, 2003, p. 17)

Diferentes discursos eram construídos para consolidar a proposta de que o cuidado corporal era necessário para a aquisição e a preservação da beleza, da saúde e também da força produtiva ${ }^{5}$. Os corpos valorizados eram aqueles pautados na estética clássica, na simetria e na associação da beleza com a prática de atividades físicas. Soares (2011) indica que, nesse cenário, as roupas eram produzidas pensando na ideia de "natural" e "higiênico" para mostrar e destacar a estrutura do corpo - não falamos mais em enchimentos e suportes externos, mas no próprio corpo como apoio das vestes, silhueta enfatizada, peles à mostra, especialmente no verão carioca, como sugere a seção "L de Elegância" da revista Para todos, em seu número 631, de janeiro de 1931, ao indicar que o "maillot", já não mais novidade, tornava-se cada vez mais curto, transparente e decotado:

o 'maillot' já não é novidade e, embora cada vez mais curto, cada vez mais pequenino e transparente, mais transparente e mais decotado [...] foi um sucesso há dois annos, quando começou a desaparecer em tamanho e deixar à mostra, o mais possível, pernas e braços, colo e costas [...]. (L DE ELEGÂNCIA, 1931, p. 36, grifo nosso).

O movimento também era um fator fortemente considerado nas roupas femininas que permitiam maior liberdade, geralmente confeccionadas em tecidos leves, com mangas curtas, maior aderência e transparências. Como observa Victor de Melo (2011), à medida que o corpo

\footnotetext{
${ }^{4}$ Como indica Denise Sant'anna (2016), o magricela destoava da proposta moderna de ser saudável e forte, representando com frequência a miséria, a fraqueza e a desgraça ou o sertanejo pobre.

No decorrer dos anos, a promoção do "aperfeiçoamento da raça" tornava-se mais acentuada, sobretudo com a eugenia sendo entendida como ciência. Nancy Stepan (2004, 2005) indica que, no contexto da América Latina, a eugenia esteve pautada na hereditariedade com foco em transformações sociais direcionadas na busca de uma "verdadeira nacionalidade". Havia o controle matrimonial exercido por meio de exames médicos e certificados e pela restrição de uniões consideradas incompatíveis, quer por doenças consideradas hereditárias, quer por "vícios sociais". Cabe destacar que a medicina se fortalece também nesse contexto, tornando-se um guia de vida, disseminando uma série de regras justificadas pelo conhecimento sobre o funcionamento do organismo e das enfermidades (COURTINE, 2011).
} 
se mostrava, tornava-se exposto, aumentava-se a atenção em torno dele, o que resultou em uma sujeição às normas de comportamento. Nesse mote, elegância, beleza, saúde e magreza, categorias essenciais para a construção da autorrealização feminina, estabeleciam-se com discursos que prometiam a possibilidade de transformar toda mulher em "bela".

Nas seções dedicadas à moda, ao cinema e aos "assumptos femininos" das três revistas figuravam croquis de moda, com ilustrações de mulheres mais funcionando como cabides de roupas em função da ausência de identidade - ou pela imposição de uma identidade única -, contribuindo para a formação do estereótipo feminino. As fotografias das atrizes hollywoodianas também podem ser comparadas aos croquis, mulheres distintas, mas semelhantes em aparência, brancas, muitas vezes loiras, decotes acentuados nos vestidos de gala, promovendo a manutenção dos imperativos sobre o corpo feminino. A beleza e a elegância surgiam como uma obrigação a ser cumprida.

\section{A mulher gorda na imprensa ilustrada}

Como sugere Denise Sant'anna (2016), nas primeiras décadas do século XX, as pessoas corpulentas apareciam na imprensa nacional como fenômenos vivos, seguindo a tendência dos Estados Unidos e de alguns países europeus (mais especificamente França e Inglaterra), da exposição da anormalidade como entretenimento (COURTINE, 2011). Nesse contexto, a percepção da gordura como patologia ainda não havia sido generalizada, sendo comum homens e mulheres gordos carregarem a ideia do cômico ou do surpreendente. As rotundas pareciam ser alvo ainda maior do humor masculino, como aponta Sant'anna nos trechos da revista Careta:

[...] havia quem escrevesse que a pior maneira de sentir calor era casar com uma gorda, sendo que as magras eram mais resistentes, pois 'osso não derrete'. Nos anos 1920, as magrinhas que apareciam nos bailes e festas da capital brasileira lembravam 'aves melindrosas', que jamais perdiam a graça [...]. (SANT’ANNA, 2016, p. 45)

As muito magras também não escapavam das piadas, recebendo apelidos como "varapau" ou "bacalhau", o que significava a predileção pelas curvas "no lugar certo", como sugeriam os colunistas. À medida que o corpo se desnudava para o banho de mar e o bronze na areia, intensificava-se o olhar sobre as imperfeições construídas pelos discursos estéticos. Na década de 1920, ainda era possível ver em muitas fotografias mulheres robustas e corpulentas de maiô (figura 4) ou até mesmo ilustrações que as tratavam de maneira positiva, com descontração, mas assim que a "obesidade" passou a ser tida como uma doença séria, que roubava anos de vida, propagandas de remédios e de produtos de beleza em favor da magreza se disseminaram na imprensa ${ }^{6}$.

\footnotetext{
"Na década de 1930, circulavam propagandas sobre o uso da Lipolysina "Henning" com ilustrações que apresentavam a mulher elegante e esbelta representando felicidade e leveza e a gorda denotando falta de mobilidade e fora de moda (GOELLNER, 2003).
} 


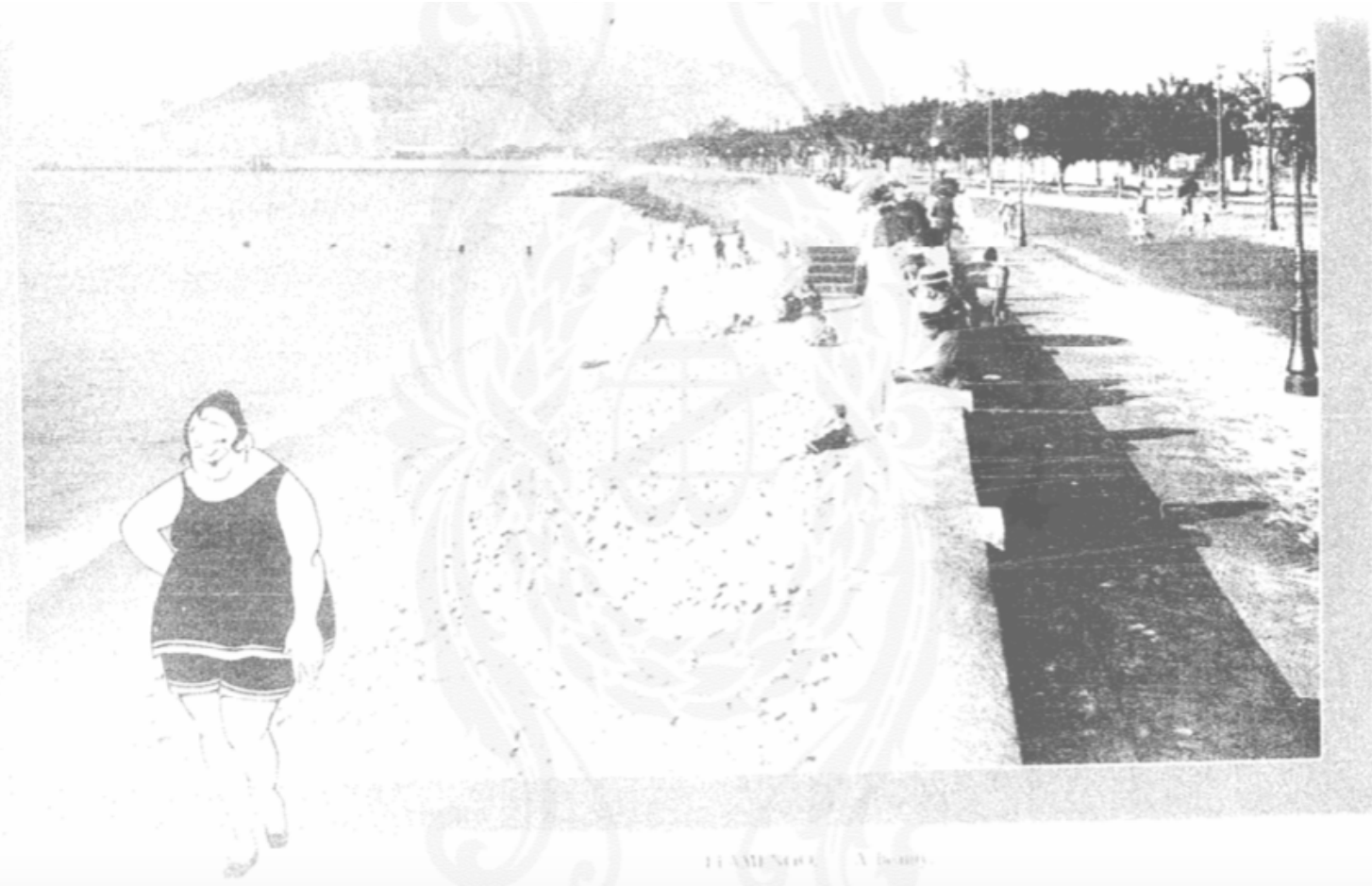

FONTE: Careta, Rio de Janeiro, 2 set. 1922, p. 27-28. Ilustração: J. Carlos. Disponível em: http://objdigital. bn.br/acervo_digital/div_periodicos/careta/careta_1922/careta_1922_741.pdf. Acesso em: 11 jan. 2018.

Apesar de os ideais de esbelteza e tônus muscular se intensificarem na década de 1930, apenas uma minoria buscava se adequar, já que no país a gordura persistiu como sinônimo de formosura durante décadas (SANT'ANNA, 2016). Ainda assim, propagandas espalhavam a crença de que uma cintura de "pilão" remetia à juventude e à inocência, fazendo com que ginásticas direcionadas para a região se popularizassem assim como as cintas que prometiam realocar e modelar a gordura em diversas partes do corpo, incluindo a região abdominal. Na Para todos, as cintas ilustradas carregavam frases mais negativas do que afirmavam elegância e forma impecável da silhueta deformada pela obesidade ${ }^{7}$.

Na edição de 11 de janeiro de 1930 de $O$ Malho, as "estrellas" de Nova York posavam em regatas e shorts de cores claras se exercitando nos aparelhos inovadores da época (figura 5). Mais uma vez, chamamos a atenção para a construção do estereótipo da mulher branca, com maquiagem acentuada e cabelos curtos e predominantemente magra, sobretudo para os padrões da época.

\footnotetext{
Para todos, 1928, p. 12. Disponível em: http://objdigital.bn.br/acervo_digital/div_periodicos/ para_todos/para_todos_1928/para_todos_474.pdf. Acesso em: 13 ago. 2018.
} 


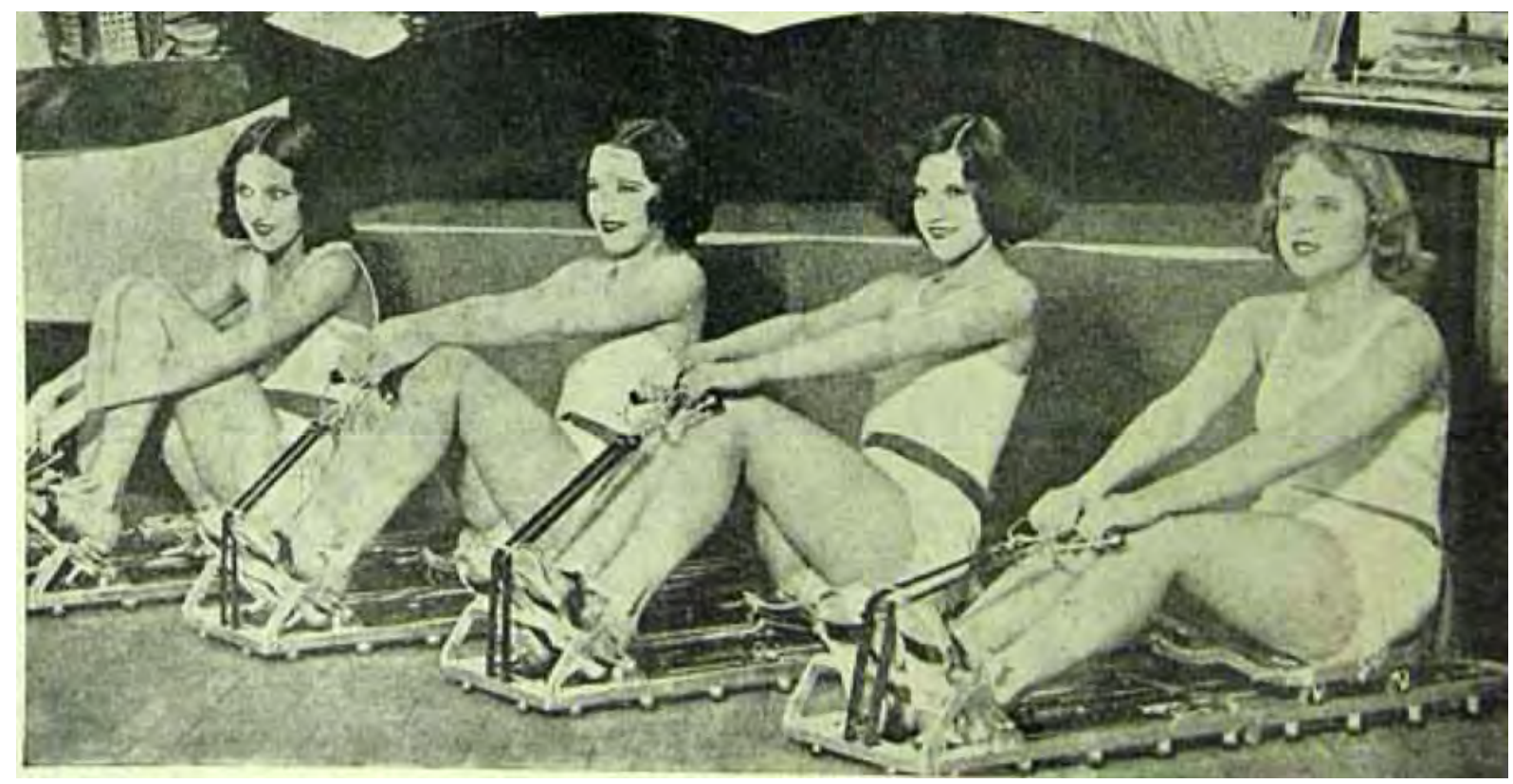

FONTE: Assumptos internacionaes. O Malho, Rio de Janeiro, n. 1426, 11 jan. 1930,

p. 18. Disponível em: http://objdigital.bn.br/acervo_digital/div_periodicos/ malho/malho_1930/malho_1426.pdf. Acesso em: 11 jan. 2018.

O Malho assim como Careta trazia o teor humorístico e satírico, principalmente tratando de assuntos políticos com forte crítica, mas não deixando de destacar as notícias da cultura carioca e as fortes influências vindas principalmente dos Estados Unidos e da França.

De fato, o peso cada vez mais estava relacionado à idade e para permanecer jovem e bela, a mulher deveria estar magra, como mostram o texto e a ilustração (figura 6) na Careta:

Há pessoas que quando veem que estão engordando com a idade, consolam-se dizendo: "Deve ser assim mesmo, com cincoenta anos não posso ter o mesmo pêso que tinha aos trinta". Sinto muito desapontá-las; mas não só elas podem, mas até devem conservar o mesmo número de quilos que tinham na mocidade. Se conseguirem emagrecer um pouquinho, tanto melhor, para a "linha" e para a saúde. (CARETA, 1949, p. 13)

No fim da década de 1940, o discurso médico ganhava maior autoridade na regulação dos corpos e era frequente nos textos a citação de alguma recomendação médica sobre emagrecer ser benéfico para a digestão e a circulação e para manter a aparência mais jovem, já que de pesado bastaria a idade. A ilustração de J. Carlos, que acompanha o texto citado, nada ingênua, revela uma mulher gorda, com cabelos desordenados e bochechas coradas, de avental, envergonhada, tentando esconder o corpo com as mãos. 


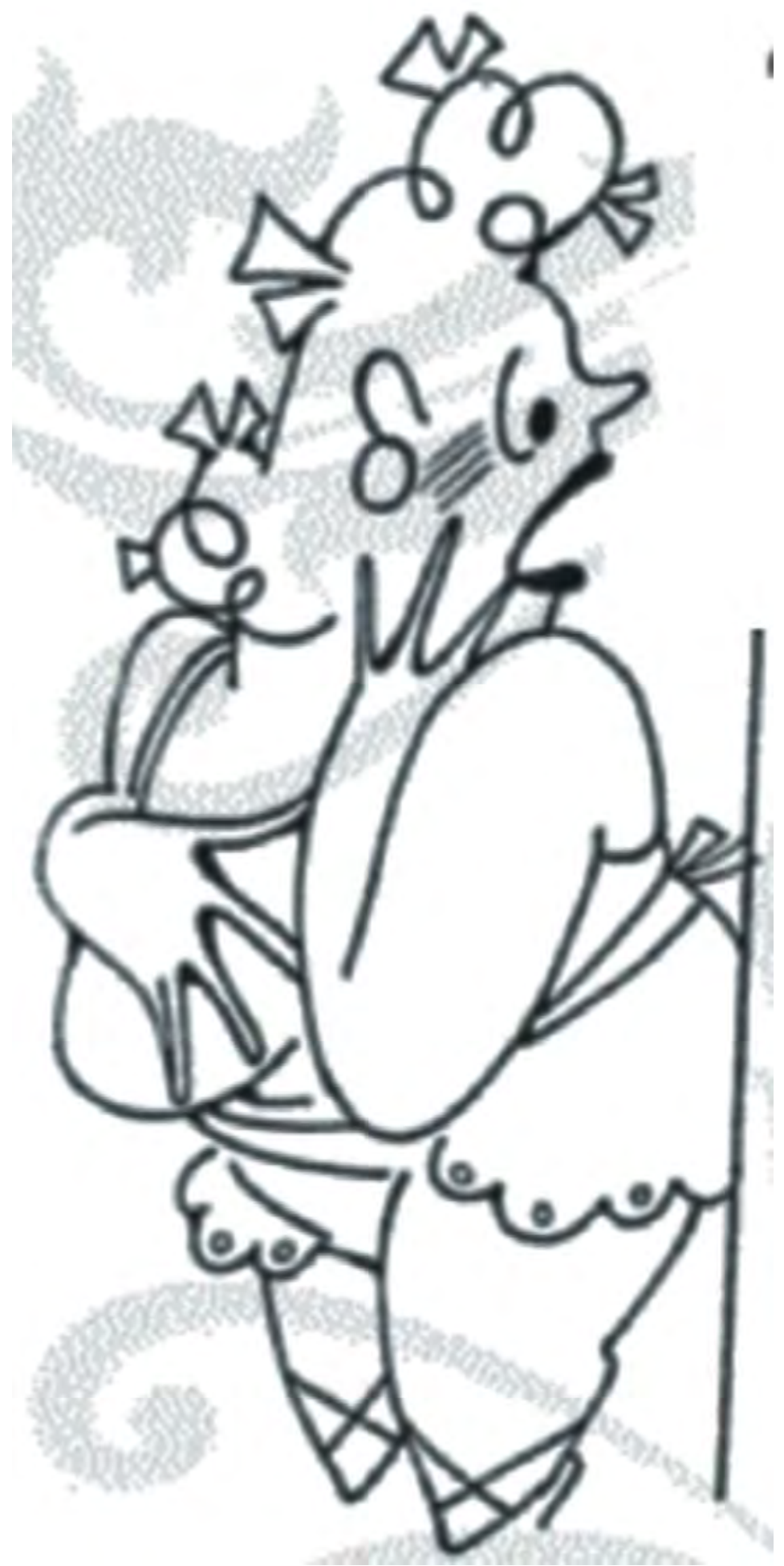

FONTE: Entre nós. Careta, Rio de Janeiro, n. 2125, 19 mar. 1949, p. 13. Disponível em: http://objdigital. bn.br/acervo_digital/div_periodicos/careta/careta_1949/careta_1949_2125.pdf. Acesso em: 11 jan. 2018. 
Com maior frequência, recomendações sobre como comer sem engordar faziam parte das pautas, atraindo as leitoras com dicas de consumo dos alimentos certos para ficar "elegante" sem brigar com a balança, manter o glamour das "estrellas" por meio de exercícios e práticas esportivas ensinados via fotografias com o passo a passo dos movimentos. A vigilância começava a tomar conta das corpulentas no lazer, na moda, no comportamento. A gordura era associada ao feio, à velhice, ao desajuste da sociedade moderna, acelerada e ávida por movimento. Como indicam Elizabeth Kobayashi e Gilberto Hochman (2015), ainda que a propaganda de produtos de natureza farmacêutica e de higiene e limpeza oferecesse a possibilidade de comprar saúde embalada nos anos 1920 e 1930, foi a partir da década de 1940 que houve "a aceleração no processo, tanto de produção desses produtos como de sua divulgação nos meios de comunicação, em especial em revistas ilustradas semanais" (KOBAYASHI; HOCHMAN, 2015, p. 69). Sant'anna (2016) comenta que a nova visão higiênica do corpo também acabava com a ideia de que as mulheres em fase de amamentação devessem comer mais do que o costume, fazendo com que a insistência sobre a estética tivesse mais importância que o medo de adoecer. Nesse contexto, emagrecer (mesmo com inúmeros casos de fome no país) "ganhou o aspecto de uma necessidade urgente, ampliada pela propaganda em torno dos martírios da obesidade e da necessidade de controlar o próprio peso" (SANT'ANNA, 2016, p. 14).

Como conclusão desta seção, encerramos constatando que o lugar mais frequente da mulher gorda na imprensa ilustrada carioca entre 1920 e 1940 era o de desvio do corpo ideal, normativo, móvel, dinâmico e saudável. A mulher gorda, ainda que de maneira prematura, associava-se à exclusão, ao envelhecimento, ao descuido, mesmo com inúmeros incentivos ao uso de xaropes para engordar - fugia-se da magreza esquelética ao mesmo tempo que se evitava a corpulência, reforçando a valorização de um corpo torneado, musculoso e atlético.

\section{Últimas considerações}

As revistas ilustradas, cada uma à sua maneira, contribuem para a compreensão do imaginário cultural brasileiro contemporâneo que resulta em desdobramentos de elementos da modernidade. Sob a ótica de autoridades masculinas, aos poucos, o corpo feminino se conformava a um padrão esguio, "enxuto", livre das deformações da gordura. Tornava-se “jovem" por ser magro, mas não deveria ser "reto como uma tábua”, precisava ser ao mesmo tempo longilíneo e curvilíneo, seguir, de certa forma, os cânones gregos, porém se destacando no bronze. A simetria e os cuidados com a aparência, que iam desde práticas esportivas até embelezamento da cútis, ingestão de xaropes e medicamentos que desengorduravam o fígado e contribuíam para a formosura, afirmavam as novas regras comportamentais paradoxais que dançavam entre os prazeres da carne, da diversão e do lazer ao aprisionamento das recomendações do campo da educação física e da medicina, ao conjunto das "servidões corporais" (MOULIN, 2011).

A combinação da moda com o esporte, do turismo com o glamour cinematográfico aos poucos desvelava o corpo, o que contribuiria, alguns anos mais tarde, para que a dieta se tornasse algo unanimemente compartilhado e a silhueta magra altamente desejada. As mulheres que apareciam nas revistas, em fotografias ou ilustrações, traziam consigo a 
construção de olhares pautados em convenções e estereótipos, limitadores de possibilidades individuais e sociais. São imagens que reafirmam os valores dominantes, a hierarquia entre os sexos.

Tendo se passado quase um século, ainda nos deparamos com um cenário similar, embora hoje as imagens e os discursos apresentados nos lancem para novas maneiras de pensar a construção do corpo, da moda, da imprensa, da medicina, da mulher. Em termos de desvios, o corpo gordo nunca foi tão representativo. Em termos de beleza, o corpo magro e cada vez mais torneado, musculoso, nunca foi tão almejado. Novos olhares surgem diante dos corpos enxutos e desnudos, novos corpos surgem diante dos olhares atentos e discriminatórios.

\section{Referências}

ASSUMPTOS internacionaes. O Malho, Rio de Janeiro, n. 1426, 11 jan. 1930, p. 18.

BARTKY, Sandra. Foucault, femininity and the modernization of patriarchal power. In: CONBOY Katie; MEDINA Nadia; STANBURY Sarah (orgs.). Writing on the body: female embodiment and feminist theory. Nova York: Columbia University Press, 1997, p. 129-154.

CARETA. Rio de Janeiro: 2 set. 1922, p. 27-28 e p. 32-33. Disponível em: http://objdigital. bn.br/acervo_digital/div_periodicos/careta/careta_1922/careta_1922_741.pdf. Acesso em: 11 jan. 2018.

COURTINE, Jean-Jacques. O corpo anormal: história e antropologia culturais da deformidade. In: CORBIN, Alain; COURTINE, Jean-Jacques; VIGARELLO, Georges (orgs.). História do corpo: as mutações do olhar. O século XX. 4. ed. Petrópolis: Vozes, 2011.

ENTRE nós. Careta, Rio de Janeiro, n. 2125, 19 mar. 1949, p. 13.

FOUCAULT, Michel. Vigiar e punir: nascimento da prisão. 20 ed. Petrópolis: Vozes, 1999.

GALERIA dos artistas da tela. Careta, Rio de Janeiro, n. 1385, p. 36, 5 jan. 1935. Disponível em: http://objdigital.bn.br/acervo_digital/div_periodicos/careta/careta_1935/careta_1935_1385. pdf. Acesso em: 9 jan. 2019.

GALERIA dos artistas da tela. Careta, Rio de Janeiro, n. 1543, p. 31, 15 jan. 1938. Disponível em: http://objdigital.bn.br/acervo_digital/div_periodicos/careta/careta_1938/ careta_1938_1543.pdf. Acesso em: 9 jan. 2019.

GOELLNER, Silvana. Bela, maternal e feminina: imagens da mulher na revista Educação Physica. Ijuí: Ed. Unijuí, 2003. 
KOBAYASHI, Elizabeth; HOCHMAN, Gilberto. O “CC” e a patologização do natural: higiene, publicidade e modernização do Brasil do pós-Segunda Guerra Mundial. Anais do Museu Paulista: história e cultura material, n. 23, v. 1, p. 67-89. Disponível em: https://doi. org/10.1590/1982-02672015v23n0103. Acesso em: 26 jul. 2019.

L de Elegância. Para Todos, Rio de Janeiro, n. 629, 3 jan. 1931, p. 34. Disponível em: http://objdigital.bn.br/acervo_digital/div_periodicos/para_todos/para_todos_1931/para_ todos_629.pdf. Acesso em: 9 jan. 2018.

L de Elegância. Para Todos, Rio de Janeiro, n. 631, 17 jan. 1931, p. 36. Disponível em: http://objdigital.bn.br/acervo_digital/div_periodicos/para_todos/para_todos_1931/para_ todos_631.pdf. Acesso em: 9 jan. 2018.

LIPOVETSKY, Gilles. Da leveza: rumo a uma civilização sem peso. 1. ed. São Paulo: Amarilys, 2016.

MELO, Victor Andrade de. 0 corpo esportivo nas searas tupiniquins: panorama histórico. In: DEL PRIORE, Mary; AMANTINO, Marcia (orgs). História do corpo no Brasil. São Paulo: Editora Unesp, 2011.

NOGUEIRA, Clara. Revista Careta (1908-1922): símbolo da modernização da imprensa no século XX. Miscelânea. v. 8, jul./dez. 2010. Disponível em: http://www.assis.unesp.br/ Home/PosGraduacao/Letras/RevistaMiscelanea/v8/clara.pdf. Acesso em: 10 jan. 2019.

MOULIN, Anne-Marie. O corpo diante da medicina. In: CORBIN, Alain; COURTINE, JeanJacques; VIGARELLO, Georges (orgs.). História do corpo: as mutações do olhar. 0 século XX. 4. ed. Petrópolis: Vozes, 2011.

PARA Todos. Rio de Janeiro: n. 474, 14 jan. 1928. Disponível em: http://objdigital.bn.br/ acervo_digital/div_periodicos/para_todos/para_todos_1928/para_todos_474.pdf. Acesso em: 13 ago. 2018.

REIS, Nelio. A festa nas praias. Careta, Rio de Janeiro, n. 1543, v. 1, 1938, p. 28-29.

SALVETTI, Xenia. As roupas nas práticas corporais e esportivas: a educação do corpo entre o conforto, a elegância e a eficiência (1920-1940). Projeto história. São Paulo, n. 49, abr. 2014, p. 435-444.

SANT'ANNA, Denise. Gordos, magros e obesos: uma história de peso no Brasil. São Paulo: Estação Liberdade, 2016.

SOARES, Carmen Lúcia. As roupas nas práticas corporais e esportivas: a educação do corpo entre o conforto, a elegância e a eficiência (1920-1940). Campinas: Autores Associados, 2011, 148p. 
SOHN, Anne-Marie. 0 corpo sexuado. In: CORBIN, Alain; COURTINE, Jean-Jacques; VIGARELLO, Georges (orgs.). História do corpo: as mutações do olhar. 0 século XX. 4. ed. Petrópolis: Vozes, 2011.

STEPAN, Nancy. Eugenia no Brasil, 1917-1940. In: HOCHMAN, Gilberto.; ARMUS, Diego. (orgs.). Cuidar, controlar, curar: ensaios históricos sobre saúde e doença na América Latina e Caribe [online]. Rio de Janeiro: Editora Fiocruz, 2004. Disponível em: http://books.scielo. org/id/7bzx4/pdf/hochman-9788575413111-11.pdf. Acesso em: 25 jul. 2019.

STEPAN, Nancy. "A hora da eugenia" raça, gênero e nação na América Latina. Rio de Janeiro: Editora Fiocruz, 2005.

VIGARELLO, Georges. Treinar. In: CORBIN, Alain; COURTINE, Jean-Jacques; VIGARELLO, Georges (orgs.). História do corpo: as mutações do olhar. 0 século XX. 4. ed. Petrópolis: Vozes, 2011. 